\title{
VESTÍGIOS DA COSMOLOGIA DE EMPÉDOCLES EM FONTES LATINAS DOS SÉCULOS XII-XIII ${ }^{1}$
}

\author{
Evaniel Brás dos Santos \\ UNICAMP
}

\begin{abstract}
Resumo: O propósito deste artigo é analisar a expressão que assegura a presença de partes da cosmologia de Empédocles no Ocidente latino nos séculos XII-XIII, qual seja, creatiomundi, esta

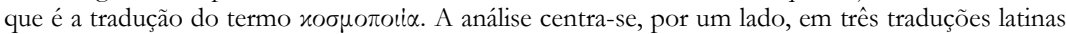

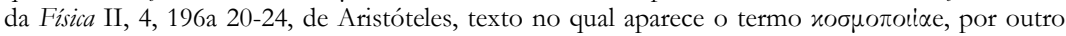
lado, em partes da obra de Tomás de Aquino na qual o autor discute a cosmologia de Empédocles. Para tanto, o texto é composto de três partes. Na primeira apresento o problema

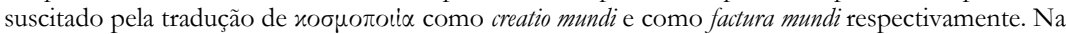
segunda, por seu turno, exponho os termos que viabilizam uma certa visão de conjunto da cosmologia de Empédocles no século XIII. Enfim, na terceira parte, apresento brevemente o sentido da noção de mundo e sua possível configuração para Empédocles.
\end{abstract}

Palavras-chave: Empédocles; cosmologia; mundo; fonte latina.

\begin{abstract}
The aim of this article is to analyse the expression that confirms the presence of traces of Empedocles' cosmology in the Latin West in the $12^{\text {th }}-13^{\text {th }}$ centuries, that is, creatio mundi, this

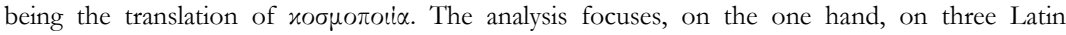

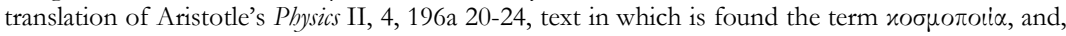
on the other hand, in parts of Thomas Aquinas' work where the author discusses the cosmology of Empedocles. For this purpose, the text is divided in three parts. Firstly, I present the problem

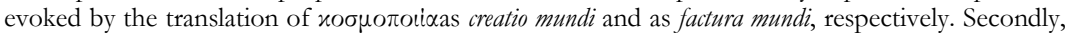
I expound the terms that make possible a certain vision of the whole of Empedocles' cosmology in the $13^{\text {th }}$ century. And thirdly, I show with brevity the meaning of the concept of world and its possible configuration for Empedocles.
\end{abstract}

Keywords: Empedocles; cosmology; world; latinsource.

Entre os séculos XII-XIII surgiram cinco versões latinas da Física de Aristóteles, a saber: (1) Tiago de Veneza (séc. XII) - grego-latim (Vetus); (2) a anônima incompleta, livros I-II. 2, (séc. XII) - grego-latim (Vaticana); (3)

1 Este trabalho foi apoiado pelo CNPq sob o número 460353/2014-4, Edital MCTI/CNPq/Universal $14 / 2014$. 
Gerardo de Cremona (séc. XII) - árabe-latim; (4) Miguel Escoto (séc. XIII) árabe-latim; (5) Guilherme de Moerbeke (séc. XIII) - grego-latim. ${ }^{2}$ Dentre estas traduções, duas possuem edição crítica: a Vaticanae a Vetus. Lamentavelmente, a Vaticana não é integrada neste artigo porque não possui o capítulo 4 da Física II, razão pela qual concentro-me na Vetus. É bastante significativa a diferença entre as traduções medievais e as traduções modernas de Physica II, 4 196a 20-24, como pode ser observado no seguinte quadro (o negrito nos termos é um acréscimo meu):

\begin{tabular}{|c|c|c|}
\hline 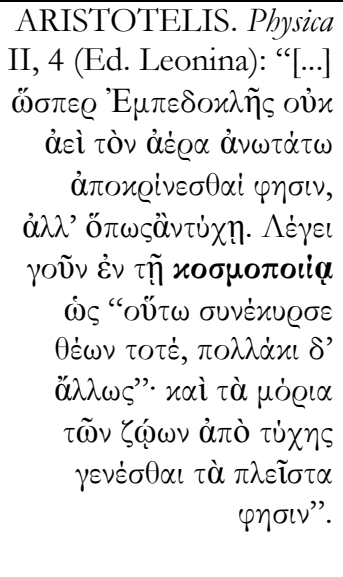 & 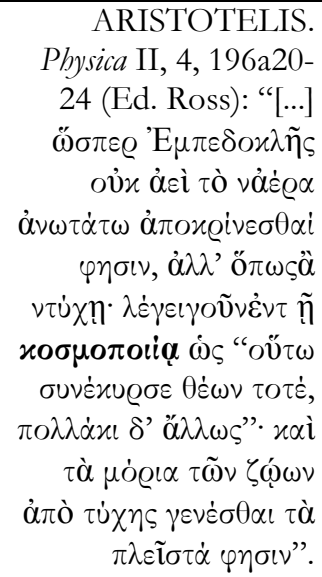 & $\begin{array}{r}\text { ARISTOTELES } \\
\text { LATINUS (V etus). Physica } \\
\text { II, 4: “[...] sicut } \\
\text { Empedocles, non semper } \\
\text { aerem aggregari superius } \\
\text { dicunt, sed ut contingit. } \\
\text { Dicit igitur in mundi } \\
\text { creatione quod «sic } \\
\text { collisit se currens tunc, } \\
\text { multo tiens autem aliter»; } \\
\text { et parte animalium a } \\
\text { fortuna fieri plurimas”. }\end{array}$ \\
\hline $\begin{array}{r}\text { ARISTOTLE. Physics II, 4, } \\
\text { 196a20-24 (tradução } \\
\text { Hardie e Gaye): “[...] as } \\
\text { Empedocles does when he } \\
\text { says that the air is not } \\
\text { always separated into the } \\
\text { highest region, but 'as it } \\
\text { may chance'. At any rate } \\
\text { he says in his cosmogony } \\
\text { that 'it happened to run } \\
\text { that way at that time, but it } \\
\text { often ran otherwise.' He } \\
\text { tells us also that most of } \\
\text { the parts of animals came }\end{array}$ & $\begin{array}{r}\text { ARISTÓTELES. Física, } \\
\text { II, 4, 196a20-24 (trad. } \\
\text { Martínez): “[...] como em } \\
\text { el caso de Empédocles, } \\
\text { quien decía que el aire no } \\
\text { está siempre separado } \\
\text { em lo más alto, como si } \\
\text { fuera u nhecho fortuito. } \\
\text { Y disse em su } \\
\text { Cosmogonía: «así fue } \\
\text { como a veces tuvo } \\
\text { casualmente su } \\
\text { recorrido, pero a veces } \\
\text { fue de outro modo». Y }\end{array}$ & $\begin{array}{r}\text { ARISTÓTELES. Física II, 4, } \\
196 a 20-24 \text { (trad. Angioni): } \\
\text { “[...] como Empédocles disse } \\
\text { que o ar não se discrimina } \\
\text { sempre para o lugar mais } \\
\text { alto, mas do modo que lhe } \\
\text { ocorrer por acaso. Ao menos } \\
\text { é certo que no poema } \\
\text { cosmogônico ele diz que 'se } \\
\text { encontra correndo às vezes } \\
\text { assim, mas frequentemente } \\
\text { de outro modo', e diz que a } \\
\text { maioria das partes dos } \\
\text { animais vem a ser por }\end{array}$ \\
\hline
\end{tabular}

2 Para uma introdução geral sobre estas traduções, com exceção da tradução de Moerbeke, cf. Bossier \& Brams, "Préface", p. xv-Ixxxiii; ver também: Bourke, "Introduction", p. xviii; De Libera, 1998, p. 361; Clagett, 1959, p. 175. Sobre a tradução de Moerbeke, ver: Brams, \& Vuillemin-Diem, 1989, p. 185-192; Brams, 1989, p. 193-220. 


\begin{tabular}{|c|c|c|}
\hline to be by chance". & $\begin{array}{l}\text { dice también que las } \\
\text { partes de los animales se } \\
\text { generan fortuitamente en } \\
\text { la mayoría de los casos". }\end{array}$ & acaso". \\
\hline $\begin{array}{r}\text { ARISTOTE. Physique II, } 4 \\
\text { (trad. Pellegrin): “[...] } \\
\text { comme Empédocle qui } \\
\text { prétend que l'air ne se } \\
\text { separe pas toujours des } \\
\text { autres éléments em allant } \\
\text { vers le haut, mais comme } \\
\text { le hasard le fait arriver. Il } \\
\text { dit en tout cas dans as } \\
\text { cosmogonie que: «Parfois } \\
\text { 'est de cette manière qu'il } \\
\text { courut les rencontrer, mais } \\
\text { souvent d'une autre } \\
\text { manière. » Et ilprétend } \\
\text { que les parties des } \\
\text { animaux, pour la plupart, } \\
\text { sont produites par } \\
\text { lehasard”. }\end{array}$ & $\begin{array}{r}\text { ARISTOTELE. Fisica II, } \\
\text { 4, 196a 20-24 (trad. } \\
\text { Russo e Longo): “[...] } \\
\text { come fa Empedocle, il } \\
\text { quale afferma che l'aria } \\
\text { sta, bem distinta, nel } \\
\text { luogo più alto, però non } \\
\text { sempre, ma secondo che } \\
\text { àpiti. Egli disse, pertanto, } \\
\text { nella sua Cosmogonia: } \\
\text { Talora essa corre in } \\
\text { modo, ma spesso corre } \\
\text { anche altrimenti } \\
\text { e sostiene che, per lo più, } \\
\text { le parti degli animali si } \\
\text { generano fortuitamente. }\end{array}$ & $\begin{array}{r}\text { ARISTOTELES. Physik II, } \\
\text { 4, 196a 20-24 (trad. Zekl): } \\
\text { “[...] So sagt etwa Empedokles, } \\
\text { nicht immer werde die Luft } \\
\text { als oberstes ausgesondert, } \\
\text { sondern (das gehe) wie es } \\
\text { sich halt fügt. Er sagt } \\
\text { jedenfalls in seiner } \\
\text { »Welterschaffung «: »So } \\
\text { sties er (scil. der Äther) } \\
\text { eilend jetzt an, vielmals aber } \\
\text { anders. «Und von den } \\
\text { Teilen der Tiere behauptet er } \\
\text { ja auch, sie entstünden } \\
\text { meistenteils aus zufälliger } \\
\text { Fügung”. }\end{array}$ \\
\hline
\end{tabular}

A distinção terminológica entre a tradução Vetus e as traduções

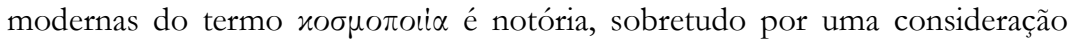
que referencia o quão a filosofia escolástica apreciou o termo creatio. ${ }^{3}$ As

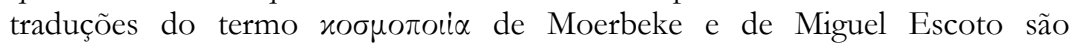
diferentes entre si. O primeiro traduz do seguinte modo:

[...] como Empédocles, diz que nem sempre o ar se congrega no alto, mas conforme a contingência. Diz, pois, na criação do mundo que [o ar] assim ocorrendo se condensa, mas diferentemente de outros modos e que muitas partes dos animais se fazem por acaso. ${ }^{4}$

\footnotetext{
${ }^{3}$ Por questões de escopo, não discuto neste artigo questões referentes ao "Empédocles histórico" ou "Empédocles grego", pois este estudo centra-se em fontes latinas, mas precisamente, o estudo preocupa-se com alguns fragmentos em latim que se configuram como fontes para a cosmologia de um autor antigo que poderia ser designado de "Empédocles latino". Sobre o Empédocles histórico, ver: O'Brien, 1969; Bollack, 1965-1969; Zariropulo, 1953. Ademais, para determinados aspectos do pensamento de Empédocles (grego), assim como para aspectos do contexto histórico, além de Jaeger, 1953, ver os textos de Vernant e Mondolfo presentes na bibliografia.

4 "[...] sicut Empedocles non semper aerem congregari superius dicit, secundum ut contingit. Dicit enim in mundi creatione quod sicut collisit se currens tunc, multotiens autem aliter et partes animalium a fortuna ait fieri plurimas".
} 
O segundo, por sua vez, registra:

[...] como fez Empédocles. Quando disse que o ar nem sempre se agita no alto, mas do modo em que se encontre. Diz, pois, ao falar do fazer-se do mundo, estas palavras, que assim acontece por acaso [com o ar], como cresce naquele momento, e casualmente é de outro modo. E diz que nos membros dos animais muito ocorre por acaso. ${ }^{5}$

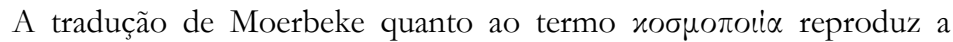
tradução Vetus. Ambas não dão a entender que tal termo trata-se de um "evento", isto é, da "criação" do mundo, o que pode indicar que a expressão "creatione mundi" é a designação de um texto, não um conceito. Miguel Escoto,

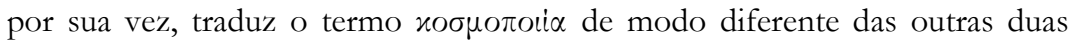
traduções. Com efeito, dificilmente a expressão "fazer-se do mundo" (factura mundi) possa ser entendida de outro modo senão afirmando o "vir-a-ser" do mundo. Na verdade, no meu entender, é impossível que a passagem, na tradução de Miguel Escoto, denote outra coisa senão a "criação" do mundo. Nesse contexto específico, factura e creatio são sinônimos. Nele, está suposto que há um "evento" cujo efeito é o mundo, embora não haja um creator (criador). A "criação" ou "fazer-se" do mundo, entretanto, como se observa pela passagem seria uma tese que Aristóteles atribui a Empédocles e não uma tese que Aristóteles sustente. Nesse caso, para os leitores dos séculos XII-XIII que possuíam a(s) tradução(es) do(s) texto(s) em mãos, Aristóteles possui conhecimento de que o mundo é "criado", no caso citado, para Empédocles, embora o mestre do Liceu não afirme a "criação" do mundo, como é manifesto pela leitura integral da Pbysica II, 4.

Na Physica II, 4, Aristóteles (Vetus) investiga se a sorte (fortuna) e o acaso (casus) podem ser ditos causa (causa). No que tange à parte que antecede a passagem em questão, Aristóteles afirma que alguns (quidam) negam que a sorte seja causa, havendo sempre uma causa determinada (causa determinata) para tudo o que ocorre, incluindo os eventos cotidianos. Ademais, os anônimos (quidam) recorreriam a um fato para negar que a sorte seja causa: os antigos sábios (antiqui sapientiores) que investigaram as causas da geração e corrupção não se pronunciaram sobre a sorte, o que indica que ela não é causa. Entretanto, essa concepção antiga (antiqua ratio), afirma Aristóteles com ironia, é admirável (mirabile), pois a sorte e o acaso devem ser entendidos como causas. Nesse sentido, a concepção antiga não sustentava que a sorte fosse

${ }^{5}[$ [...] ut fecit Empedocles. Cum dixit, quod aer non semper excutitur ad superius sed quomodocumque sit. Dicit enim, cum loquitur de factura mundi, haec verba, sic accidit casu, ut crevit in illo tempore, et forte est alio modo. Et dicit, in membris animalium plura accidunt casu". 
causa, tal como era a amizade (amicitia), a guerra (bellum), o fogo (ignis) e o intelecto (intellectus), o que se mostra, segundo Aristóteles, como inadequado:

Portanto, é inconveniente, ou não entenderam que são ou
entenderam e abandonaram, e às vezes é usada deste modo,
como Empédocles, dizem que nem sempre o ar se agrega no
alto, mas por contingência. Diz, com efeito, na criação do
mundo que $\left[\begin{array}{l}o \\ \text { ar }]\end{array}\right.$ assim ocorrendo se condensa, mas
diferentemente de outros modos; e muitas partes dos animais
se fazem por acaso. (Physica (Vetus) II, 4, p. $65,1.4-8){ }^{6}$

Aristóteles (Vetus) aponta uma possível incongruência: Empédocles sustenta que o acaso não é causa, como era comum à concepção antiga (antiqua ratio), porém ele emprega o acaso como causa. São dois exemplos citados, a condensação do ar, que seria efeito não de uma causa determinada, mas consequência da contingência e, por sua vez, a formação das partes dos animais: produto do acaso. É nesse contexto da manifestação da possível incongruência que Aristóteles se refere ao texto de Empédocles que trata da "criação" do mundo. Há, pois, duas discussões intimamente vinculadas: a "criação" do mundo, uma discussão mais geral, e os casos elencados do ar e dos animais, uma discussão mais específica. Quanto à discussão geral, Aristóteles não se pronuncia na passagem citada, ele é neutro. Diferentemente, na discussão específica, ele aponta a possível incongruência de Empédocles.

$\mathrm{Na}$ sequência de Physica II, 4, Aristóteles (Vetus) volta a discutir com os anônimos (quidam). Estes afirmariam que o céu e o conjunto dos mundos são causados por acaso ("sunt autem quidam qui celi buius et mundanorum omnium causantur esse casum”). O sentido de causalidade, nesse contexto, também possui um caráter geral e um específico ("acasu enim fieri cursum et motum discernentem et statuentem in bunc ordinemomne"; (Physica (Vetus) II, 4, p. 65, 1. 10, p. 66, 1. 1). O acaso, para os anônimos, segundo Aristóteles, é a causa que faz (fieri) o curso (cursus) e o movimento (motus) que separa (discernentem) e institui (statuentem) a ordem do todo (ordoomne), ou seja, do céu e dos mundos. Semelhante ao modo como procede com Empédocles, Aristóteles não se pronuncia sobre a discussão geral; mais uma vez ele é neutro. Ele centra-se na discussão específica, qual seja, aquela que trata sobre o céu (celo), os animais (animalia) e as plantas (plantas). Nesse sentido, ele não se põe contra a tese ancestral (antiqua ratio) segundo a qual há uma causa para "o curso da ordem do todo" (cursus ordinem omne), seu repúdio se dirige para a incongruência dos anônimos,

6 "Inconveniens igitur est sive non putaverunt esse sive putantes reliquerunt, et hac aliquando utentes, sicut Empedocles, non semper aerem aggregari superius dicunt, sed ut contingit. Dicit igitur in mundi creatione quod «sic collisit se currens tunc, multotiens autem aliter»; et parte animalium a fortuna fieri plurimas". 
isto é, eles afirmam que o acaso é a causa da ordem do todo, porém, por um lado, afirmam que a causa do vir-a-ser (fieri) dos animais e das plantas não é o acaso, mas a natureza (natura) ou intelecto (intellectus) ou algo semelhante (buiusmodi) e, por outro, que o acaso é a causa do vir-a-ser (fierr) do céu (cf. Physica (Vetus) II, 4, p. 66, 1. 1-9). Todavia, e aqui Aristóteles se volta exclusivamente para o vir-a-ser do céu (celo fier), não há evento (fierz) no céu que ocorra por acaso (cf. Physica (Vetus) II, 4, p. 66, 1. 9-11, p. 67, 1. 1-2).

Embora Aristóteles (Vetus) na Physica II, 4, não atribua a Empédocles a sentença "cursus ordinem omne", a expressão empregada por ele (Vetus) e direcionada a Empédocles - "creatione mund" - pode subsumir o sentido

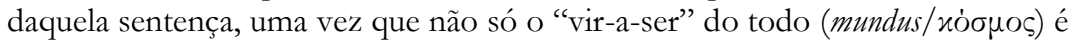
filosoficamente ininteligível sem uma organização interna, mas também o

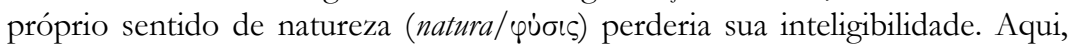
entretanto, pode parecer demasiadamente estranho ao leitor de hoje a

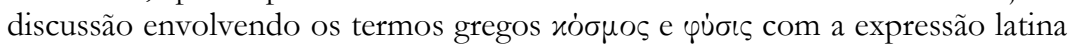
creatiomundi, sobretudo aqueles leitores que, mesmo possuindo uma sólida formação filosófica, literária e linguística, não possuem uma leitura minimamente aprofundada de dois itens, quais sejam, (i) a íntima articulação entre física e metafísica nos autores medievais e (ii) a complexidade da relação dos tradutores medievais com o texto a ser traduzido. ${ }^{7}$ Nesse último caso, não é exagero lembrar que os tradutores medievais não realizam "traduções comentadas", com notas de rodapés ou apêndices. É de uma nobreza singular a atitude de um tradutor medieval que às vezes possuía entre três e cinco termos para a mesma palavra grega, tendo que optar necessariamente por apenas um sem possuir a oportunidade de justificar o porquê de sua escolha. Assim como não é menos nobre a atitude de transliterar quando não se encontra um termo latino correspondente. ${ }^{8}$

A complexidade inerente na empreitada do tradutor medieval, que pode estar associada com as traduções dos textos de Aristóteles, incluindo a passagem de Physica II, 4, 196a 20-24, pode ser enfatizada pelas seguintes passagens de outras fontes latinas presentes nos séculos XII-XIII: 1891). ${ }^{9}$

(I) Genesis, 1,1: "No princípio criou Deus o céu e a terra". (Vulgatae,

(II) Plato latinus (Calcídio), Timaeus, 38C: “Assim, portanto, do conhecimento e habilidade de deus e disso ocorreu a geração do tempo, e da

\footnotetext{
${ }^{7}$ Sobre o primeiro item, ver meus artigos: Santos, 2014; Santos, $2015 \mathrm{~b}$.

8 Ver, por exemplo, o caso do termo grego ópuǹv transliterado pelo tradutor da Vaticana como ormen. Cf. Santos, 2014, p. 124-126.

9 "In principio creavit Deus caelum et terra [...]"
} 
vontade [dele] foram criados o Sol e a Lua, e foram feitas as cinco estrelas que se chamam 'errantes'. ${ }^{10}$

(III) Liber de causis, proposição 4: "A primeira das coisas criadas é o ser e antes dele não há algo criado”. (In: Thomas D’Aquin: Super Librum de Causis Expositio, p. 26). ${ }^{11}$

(IV) Avicenna latinus, Liber de Philosophia prima, 6, 1, A 257-8:

[...] os filósofos divinos não entendem por agente somente o princípio de movimento, tal como o entendem os filósofos naturais, mas como princípio de ser e doador dele, enquanto criador do mundo. De fato, a causa agente, quando natural, não produz o ser da coisa a não ser movendo algo segundo os modos dos movimentos. Portanto, nas ciências naturais, o que confere ser é um princípio de movimento. ${ }^{12}$

As quatro fontes latinas, como se sabe, precedem cronologicamente às traduções da Physica de Aristóteles. Embora exceda completamente ao escopo deste estudo abordar a possível influência dessas fontes na tradução de Physica II, 4, 196a 20-24, ao menos indico que não se configura numa atitude

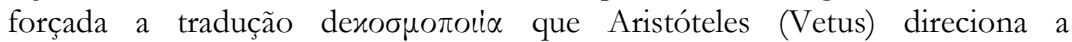
Empédocles como "creatione mundi", sobretudo quando se percebe que no Timaeus 38C, Platão, diferentemente da neutralidade de Aristóteles, sustenta a criação dos astros. ${ }^{13}$

10 "Hac ergo dei ratione consilio que huiusmodi genituram temporis volentis creari sol et luna et aliae quinque stellae quae vocantur erraticae factae sunt".

11 "Prima rerum creatarum est esse et non est ante ipsum creatum aliud".

12 "[...] divini philosophi non intelligunt per agentem principium motionis tantum, sicut intelligunt naturales, sed principium essendi et datoremeius, sicut creator mundi; causa vero agens naturalis non acquirit esse rei nisi motio nem aliquam ex modis motionum; igitur acquirens esse naturalibus est principium motus".

${ }_{13}$ Ademais, um dos primeiros a desenvolver o sentido de criação em terras propriamente gregas, segundo Sorabji, foi Crantor (morte 290 a.C; cf.Sorabji, 1983, p. 271). Para Crantor, conforme Sorabji, a instituição dos entes naturais afirmada por Platão no Timeu diz respeito à existência, ou seja, uma dependência ontológica que é exemplificada pela luz da Lua que depende da iluminação do Sol. Nesse sentido, a instituição da existência dos entes naturais não implica em afirmar um início absoluto para 0 tempo (cf. Sorabji, 1983, p. 275): "O segundo aspecto no qual platônicos e cristãos fizeram inovações diz respeito à relação da criação e da causa para o tempo. Eu discursei no capítulo 17 sobre 0 reconhecimento platônico, logo no começo com Crantor - duas gerações após Platão - que podemos dar sentido à ideia de criação sem início temporal. Todavia, eu não explicitei totalmente a enorme influência dessa ideia. Essa influência aparece surpreendentemente em Tomás de Aquino, o qual afirma que um início [temporal] do universo não se segue do fato de haver criação; nem mesmo se segue do fato da criação ocorrer a partir do nada. Isso é simplesmente um artigo da fé cristã". (Sorabji, 1983, p. 312. Grifo do autor). Sorabji manifesta surpresa ao encontrar em Tomás a tese defendida por Crantor. Embora Sorabji não desenvolva explicitamente a possível relação direta entre Tomás e Crantor, essa relação pode ser compreendida pela mediação da tradição platônica, notadamente por Plotino representado pela plotiniana arábica (cf. Taylor, 1998, p. 222-223; p. 228- 229). Com efeito, mesmo que o "Um" e a divindade sejam distintos, (cf. Gerson, 1993, p. 568), Plotino pode ter sido um dos primeiros 
Além das traduções da Physica de Aristóteles, outros autores do século XII-XIII podem ser tomados como fontes latinas nas quais encontram-se vestígios da cosmologia de Empédocles. É o caso de Tomás de Aquino, ${ }^{14}$ que discute a passagem em questão no In Physica II, 7, n. 5. Ao considerar a passagem da Physica II, 4, 196a 20-24, ou uma parecida, Tomás no In Physica II, 7, n. 5, emprega a expressão "prima constitutione mund?" no contexto em que, mediante Aristóteles, discute com Empédocles. Como é seu costume, Tomás sempre começa sua consideração citando pequenas partes da passagem a ser lida, no caso da Physica II, 4: "Inconveniens igitur est et cetera". A expressão "inconveniens igitur est" é idêntica nas traduções Vetus e de Moerbeke e distinta da tradução de Miguel Escoto, o que conduz a crer que Tomás não tinha a tradução deste em mãos quando da redação do In Physica II, 7, n. 5.

$\mathrm{Na}$ consideração da passagem em questão da Physica II, 4, embora, ao que parece, não possuísse em mãos a tradução de Miguel Escoto, Tomás troca o termo "creatione" por "factus", termo cuja raiz é a mesma daquele empregado por Miguel Escoto: factura. Tal procedimento de Tomás merece ser investigado. Tomás, por alguma razão, teria trocado o termo conscientemente?

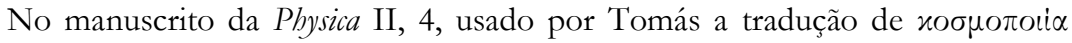
não seria "creatione mundi"? Embora uma resposta positiva para a segunda questão seja razoável, mesmo porque o termo "creatione" não aparece no In Physica II, 7, pela leitura de In Physica II, 7, n. 5, é mais razoável que Tomás tenha trocado o termo conscientemente, talvez querendo indicar que o termo "creatio" em sentido escolástico não pertence a filosofia grega, pois ele necessariamente inclui a máxima: ex nibilo esse fieri (ver a discussão mais à frente).

Tomás, de modo semelhante a Aristóteles, critica a articulação que os antigos fizeram das noções de causa, acaso e sorte, nomeadamente a crítica se dirige a Empédocles. É evidente que para Tomás a discussão dos antigos é

a nomear um tipo de operação sobre o efeito totalmente desvinculada da matéria, a saber, a "emanação" (cf. Gerson, 1993, p. 560, nota 3; embora a referência aqui não seja o texto latino, mas o grego). A relação de Tomás com a plotiniana arábica, por sua vez, foi mediada pelo Liber de causis, pois os representantes da plotiniana arábica, quais sejam, a Teologia de Aristóteles, os Provérbios dos Sábios Gregos e o Tratado sobre o Conhecimento Divino, não estavam disponíveis em tradução latina no século XIII (cf. Taylor, 1998, p. 222-223).

${ }^{14}$ As obras de Tomás serão referenciadas do seguinte modo: ST (Summae Theologiae); SCG (Summa contra gentiles); QDP (Quaestiones Disputatae de Potentia Dei); In Sent. (Scriptum Super Libros Sententiarum Magistri Petri Lombardi); DSS (De substantiis separatisad fratrem Raynaldum de Piperno); QDV (Quaestiones disputatae de Veritate); In Physica (In octo libros physicorum Aristotelis expositio); In DCM (In libros Aristotelis De caelo et mundo). DSC (De spiritualibus creaturis). In BDT (Super Boetium De Trinitate). Todas as traduções são de minha responsabilidade. 
bastante complexa, sobretudo porque, de modo inteligente, procedendo além das informações fornecidas por Aristóteles, Tomás introduz a expressão "prima constitutione mundi", a qual pode ser lida não somente no domínio da cosmologia, mas também da metafísica. A despeito do tratamento incoveniente dos antigos, aos olhos de Tomás, fato é que, mesmo de modo desajeitado, eles trataram filosoficamente sobre a instituição do mundo ("mundus est factus"; cf. In Physica II, 7, n. 5). Embora Aristóteles não se pronuncie sobre a criação do mundo, pois ele é neutro, o mestre do Liceu é uma das fontes que transmite a Tomás os primórdios do tratamento filosófico sobre a creatio. Isso ocorre, sobretudo no que toca à cosmologia de Empédocles, esta que, na pena de Tomás (cf. In Physica II, 7, n. 5), quando comparado ao tratamento presente na Physica II, 4, de Aristóteles, ganha certa sistematicidade, nomeadamente, em três itens: (i) na primeira constituição do mundo ("prima constitutione mundi"); (ii) no ordenamento das partes do universo ("ordinatur inter partes universi"); (iii) na separação dos elementos ("distinguente elementa").

É importante notar que não há qualquer distinção relevante entre "mundus" e "universus" na cosmologia de Empédocles tratada no In Physica II, 7, n. $5 .{ }^{15}$ Ambos denotam, primordialmente, o conjunto ou a totalidade das partes ou constituintes inerentes nos céus e na Terra. Nesse contexto, três questões intrigantes e necessariamente interligadas emergem, a saber: (1) o que é o mundo (ou universo) para Empédocles? (2) Se há uma configuração para ele, qual seria?(3) Qual é precisamente a função da visão e da imaginação na apreensão do sentido de "mundo" (universo) e de sua configuração, se houver? Dois itens presentes em outros textos de Tomás contribuem significativamente para o esclarecimento das questões formuladas, quais sejam, (a) o discurso empreendido na "física grega" emprega a imaginação; (b) os antiqui ("pré-socráticos"), incluindo Empédocles ${ }^{16}$, ao estabelecerem seus discursos não ultrapassaram a imaginação, ${ }^{17}$ (o que designarei aqui de "discurso natural").

A função da visão e da imaginação no discurso natural é marcada pela sentença "ex nibilo nibil fier"” ("do nada, nada é feito"; cf. SCG II, 37, n. 1130). Com efeito, pela visão entende-se que o fazer-se (fieri) de um determinado ente

\footnotetext{
${ }^{15}$ A distinção pode ser encontrada no interior do próprio pensamento tomásico. Com efeito, sobretudo noln BDT, qq. 5-6, encontro distinções relevantes não só entre mundus e universus, mas também entre mundus, universus e natura. No texto referido, mundus é entendido como a totalidade dos entes materiais. Universus, por sua vez, inclui não somente os entes materiais, mas também os entes imateriais - com exceção da divindade. Natura, enfim, é entendida como princípio interno e externo de movimento. Para uma introdução a essa discussão, ver: Santos, 2015a.

${ }^{16}$ Sempre que eu empregar o termo "antiqui", nele estará incluso Empédocles.

17 Em cinco textos distintos Tomás aborda os dois tópicos elencados: SCG, II, 37, n. 1130; DPD, q. 3, a. 5, resp.; ST, la, q. 44, a. 2, resp.; In Physica, VIII, 2; DSS, c. 9. Sobre tais passagens, ver: Santos, 2013.
} 
requer necessariamente um substrato. A transposição dessa compreensão para o domínio do mundo - nos termos que Tomás dirige aos antiqui (cf. SCG II, 37 , n. 1130), "na consideração sobre a origem das coisas" (rerum originem considerare) ou "na busca pelo princípio das coisas" (principium rerum perquirentes) - imagina-se que o mundo é feito de modo similar à visão daquele ente determinado, razão pela qual é completamente razoável a admissão no discurso natural dos antiqui de que ex nibilo nibil fieri.

O procedimento que ultrapassa a imaginação, pela leitura do texto de Tomás, é um dos elementos que funda a metafísica tomada em sentido geral, como também funda uma metafísica da criação em sentido escolástico, (entendida aqui como um "discurso supernatural"18). Mesmo nesse contexto, entretanto, a condição humana se impõe, pois é necessário apelar para a imaginação e, por consequência, para a metáfora, quando no discurso supernatural se admite que o fazer (fierı) do mundo não é uma mudança, logo que exnibilo esse fieri (cf. SCG II, 37, n. 1130).

As modalidades do discurso estão incluídas no que Tomás designa de scientiaspeculativa. Aliás, a expressão é direcionada aos primeiros filósofos (primiphilosophi) gregos, nos quais Empédocles certamente está incluso:

[...] porque à razão humana é natural ascender gradualmente do imperfeito para o perfeito. Por isso vemos, nas ciências especulativas, que os primeiros filósofos transmitiram aos seus sucessores umas doutrinas imperfeitas, que estes por sua vez transmitiram aos seus sucessores mais aperfeiçoadas. (ST, Ia-IIae, q. 97, a. 1, resp.). ${ }^{19}$

Três são as matrizes das ciências especulativas: a matemática, a física e a divina (cf. In BDT, qq. 5-6). Desde o surgimento da filosofia na Grécia, conforme a passagem, tais matrizes sofreram evolução. Interessa aqui, sobretudo, a física ou scientia naturalis, uma vez que é nela que se estuda os constituintes mais gerais do mundo, os céus e os elementos, e o próprio mundo (cf. In DCM, prooemium). Nesse sentido, dentre as ciências especulativas, não cabe à divina a investigação sobre os céus e os elementos: é tarefa da scientia naturalis (cf. In DCM, prooemium, n. 5.)Assim sendo, não se pode confundir o sentido do termo latino "cosmologia" entendido como parte da metafísica, logo, distinto da física, postulado por Christian Wolff (1679-

\footnotetext{
${ }^{18}$ Aertsen emprega a expressão "discurso transcendental", cf. Aertsen, 2012; Aertsen, 1996.

19 "[...] quia humana erationi naturale esse videtur ut gradatim ab imperfecto ad perfectum perveniat. Unde videmus in scientiis speculativis quod qui primo philosophati sunt, quaedam imperfecta tradiderunt, quae postmodum per posteriores sunt magis perfecta".
} 
1754), ${ }^{20}$ de meu emprego do termo português "cosmologia" identificado com a scientia naturalis dos antiqui, nomeadamente quanto a Empédocles.

A despeito de haver o emprego da imaginação em alguns raciocínios no domínio da matriz divina (cf. In BDT, q. 6, a.1.), lhe é próprio a intelecção sem os recursos da imaginação, é, pois, uma das maiores marcas que diferencia a scientia naturalis e a matriz divina. Dito de outro modo, Tomás ao diferenciar a razão (ratio) e o intelecto (intellectus) como potências da alma humana admite que a scientia naturalis está restrita à razão (cf. In BDT, q. 6, a. 1, arg. 14).Isso indica, a meu ver, que o estudo cosmológico empreendido na scientia naturalis não ultrapassa os sentidos e a imaginação, pois prosseguir além dessa fronteira é adentrar no domínio da matriz divina, o que retiraria a naturalidade da scientia naturalis. Nessa medida, a scientia naturalis ocupa-se exclusivamente com as formas corpóreas (formas corporum; In BDT, q. 6, a. 1, sed contra 1), estas que, mediante a imaginação, são apreendidas pela razão como "figuras sensíveis" (figuris sensibilibus; In BDT, q. 6, a. 2, prooemium).

A restrição às figuras sensíveis, de fato, é uma característica da scientia naturalis na filosofia grega nascente. Embora em outros domínios da scientia speculativa Anaxágoras tenha alcançado o incorpóreo, logo, prosseguiu além da imaginação (cf. DSS, c. 1; DSC, a. 1, resp.), dentre os antiqui, é certo que, aos olhos de Tomás, Empédocles limitou-se à scientia naturalis. Tal limitação é importante para os estudos sobre cosmologia latina devido à naturalidade da postura filosófica de Empédocles, semelhante, a meu ver, à importância de Ptolomeu para a astronomia medieval, a despeito dele não possuir uma metafísica.

Embora não se refira explicitamente a Empédocles, ele está dentre os antiqui, quando Tomás escreve:

Porém, os antigos, ignorando a força intelectiva e não distinguindo entre o sentido e o intelecto, pensaram que nada existe no mundo, além do que pode ser apreendido pelos sentidos e pela imaginação. E como a imaginação só apreende o corpo, pensaram que nenhum ente, além do corpo, pode existir [...]. (ST, Ia, q. 50, a. 1, resp.). ${ }^{21}$

O mundo é imaginado e entendido pelos antiqui como o corpo mais extenso. Semelhante a qualquer outro corpo menos extenso, o mundo possui partes e, portanto, figura (ou forma). Embora a visão seja demasiadamente limitada na percepção dos corpos bem extensos e afastados, como, por

${ }^{20}$ Cf. Wollf, 1977.

21 "Antiqui autem, ignorantes vim intelligendi, et non distinguentes intersensum et intellectum, nihil esse existima verunt in mundo, nisi quod sensu et imaginatione apprehendi potest. Et quia sub imaginatione non cadit nisi corpus, existima verunt quod nullu mens esset nisi corpus [...]". 
exemplo, as esferas celestes, ela obtém as informações suficientes da totalidade ou configuração de corpos mais próximos, viabilizando, assim, a imaginação de corpos mais extensos, como é o caso do mundo.

A compreensão do mundo como um corpo, conforme a passagem, conduziu os antiqui a negar a existência de entes incorpóreos no mundo. $\mathrm{O}$ raciocínio é bem simples: se a totalidade é corpo, as partes também são. Devese ressaltar, ademais, que, à exceção de Anaxágoras, dentre as ciências especulativas, os antiqui situam-se na scientia naturalis. Se a scientia naturalis não ultrapassa a imaginação para não perder sua naturalidade, então é muito razoável que os antiqui, por um lado, não tenham empreendido a distinção entre sentido e intelecto (sensus et intellectus) e, por outro, tenham ignorado a força de inteligir (vis intelligendi). Cobrar dos antiqui um procedimento que descaracterizaria sua postura filosófica, portanto, parece inadequado.

Percebe-se, pela leitura integral de ST, Ia, q. 50, a. 1, que Tomás situase, dentre as ciências especulativas, na matriz divina, cobrando, por esse prisma, algo que os antiqui não estão dispostos a lhe oferecer. Com efeito, da seguinte premissa "Apreender, porém, não pode ser ato do corpo nem de alguma força corpórea, porque todo corpo encontra-se aqui e agora" (ST, IaIIae, q. 97, a. 1, resp.) 22, Tomás extrai a conclusão segundo a qual "É necessário estabelecer algumas criaturas incorpóreas" (Idem) ${ }^{23}$. A incorporeidade não só excede ao escopo da scientia naturalis dos antiqui, como também, a desnaturaliza.

A postura de Tomás frente aos antiqui é paradoxal. Conforme já apresentado, Tomás afirma e reafirma que “[...] o modo de proceder da física é extraído da razão" (In BDT, q. 6, a. 1, ad14) ${ }^{24}$ e, ademais, que “[...] compreender o imaginável e o sensível pertence somente ao filósofo natural" (In BDT, q. 6, a. 1, sed contra 2) 25. Portanto, aos olhos do próprio Tomás, ascientianaturalisnão pode ultrapassar a imaginação. Entretanto, a despeito de sua consciência de que os antiqui situam-se na scientianaturalis, ele censura o fato deles não terem ultrapassado a imaginação.

\section{III}

A despeito de sua postura crítica possivelmente inadequada, é fato que os vestígios da cosmologia de Empédocles presentes na obra tomásica

\footnotetext{
22 "intelligere autem non potest esse actus corporis, nec alicuius virtutis corporeae, quia omne corpus determinatur ad hic et nunc"

23 "[...] nec esse est ponere aliquas creaturas incorporeas".

24 "[...] modus physicae sumitur a ratione [...]".

25 "[...] imaginabilia et sensibiliza comprehendere ad solum natural empertinet".
} 
conferem-lhe certa organicidade de modo que é possível adquirir uma compreensão razoável da naturalidade da cosmologia de Empédocles, para o século XIII. A visão e a imaginação, conforme já mencionado, cumprem uma função basilar.

A observação dos céus, ou o olhar para o firmamento à noite, é fundamental no estabelecimento da scientia naturalis dos antiqui. ${ }^{26} \mathrm{O}$ próprio Tomás em sua juventude admitiu que o conhecimento sobre os céus possui a visão (visum) como fonte central, pois, mesmo a compreensão do movimento depende da visão ("...quid quid de caelis cognoscimus hoc est aut per visumant per motum”; In Sent., II, d. 2, q. 2, a.1, resp.). Olhar para o firmamento é fundamentalmente dispor-se a receber a impressão celeste, a maior motivação para os antiqui elaborarem a cosmologia (scientia naturalis). ${ }^{27} \mathrm{~A}$ impressão celeste passa pelo olho e atinge (attingo) a imaginação entendida como "potência corpórea” (cf. QDV, q. 12, a. 3, ad5), podendo viabilizar, inclusive, a profecia natural (prophetia naturalis) nos "philosophi in scientia naturali" (QDV, q. 12, a. 3, ad8). É preciso notar, todavia - e aqui há outra característica que diferencia a scientia naturalis e a matriz divina - que a impressão celeste, segundo Tomás, não atinge o intelecto, mas somente a imaginação (cf. SCG III, 84, n. 2585). O filósofo natural, o físico antigo (antiquus), portanto, necessariamente está limitado nas formas obtidas pela visão e pela imaginação.

Pela compreensão da função da visão e da imaginação no estabelecimento da scientia naturalis, para os antiqui e, especialmente, para Empédocles, é possível esclarecer as outras duas questões formuladas sobre o sentido da noção de mundo e sua configuração na cosmologia empedocleana:

Fornece a segunda razão ao dizer: portanto, é inconveniente etc. E diz que é inconveniente que os antigos físicos não trataram sobre a sorte, ou pensaram que a sorte existe ou não, porque se pensaram que a sorte existe foi inconveniente que não trataram sobre ela, e se pensaram que não existe foi inconveniente que fizeram algum uso dela; como Empédocles, que diz que o ar nem sempre está condensado

\footnotetext{
26 O termo "céus" possui uma semântica complexa nos autores antigos e medievais. Conforme In DCM, prooemium, o debate sobre os possíveis sentidos de tal termo remonta a Alexandre de Afrodísias, Simplício, Siriano e Jâmblico. São três os principais sentidos de "céus" encontrados nestes autores: (i) estrelas fixas (ou última esfera); (ii) todo corpo que é movido circularmente e (iii) o próprio universo (ou mundo). É, inclusive, se apossando desse último sentido de "céus" que Tomás afirma que a Terra está no meio do céu, (cf. In BDT, q. 5, a. 3, arg. 7).

${ }^{27}$ Sem pretensões de exagero e, ademais, consciente de que se trata de uma língua que poucos latinos dos séculos XII-XIII conheciam, a seguinte observação de Vernant é muito apropriada para o estudo sobre a cosmologia dos antiqui: "[...] ver y saber son I amisma cosa; si eideîn 'ver' y eidénai 'saber' son dos formas de unmismo verbo, si eîdos 'apariencia', 'aspecto visible' significa también 'carácter propio', 'forma inteligible', es porque El conocimiento se interpreta y expresa a través del mundo de la visión. Conocer es, pues, una forma de ver". (Vernant, 1995, p. 21).
} 
sobre a terra, como se isso lhe fosse natural, e mesmo assim sendo por acaso. Diz, pois, que quando o mundo é feito e a luta separando os elementos, ocorre que o ar se condensa neste lugar, como ocorre agora e sempre será enquanto aquele mundo permanece; entretanto, em outros mundos, sustenta que é feito e é corrompido infinitamente, como dito acima, o ar é ordenado de outro modo dentre as partes do universo. E, semelhantemente, dizia que a maioria das partes dos animais se fizeram por sorte, como na primeira constituição do mundo foram feitas cabeças sem pescoço. (In Physica II, 7, n. 5). ${ }^{28}$

O sentido da duração e temporalidade do mundo (“...ita semper stante isto mundo cursum habebit') na cosmologia de Empédocles, presente na passagem citada, é intrigante. Empédocles, conforme a passagem, concebe uma "primeira constituição do mundo" (prima constitutione mundi). É possível postular que a duração e temporalidade do mundo decorrem de um evento primordial, absolutamente irrepetível, uma espécie de primeiríssima passagem do caos, a não separação dos elementos, à determinada ordem ou configuração. Nesse sentido, quanto à totalidade do mundo, embora surja do caos, ele jamais retornará ao caos. Ele muda de ordem ou configuração quanto às partes, mas em sua totalidade ele deve permanecer, caso contrário postulase uma asserção filosoficamente ininteligível, pois admitir-se-ia que há algo sem qualquer configuração por si ou por outro. Aqui, com efeito, encontra-se uma concepção empedocleana segundo a qual cada parte da totalidade do mundo é um "mundo", razão pela qual é inteligível afirmar que existem vários mundos em mutações periódicas. Nesses outros mundos, a ordem dos elementos pode não seguir aquela "deste mundo atual", a saber, a terra abaixo da água, está abaixo do ar e este abaixo do fogo, como no caso da "esfera" do ar, que poderia estar situada acima da "esfera" do fogo e não abaixo como se encontra "neste mundo atual". O que confere a naturalidade ao ar, assim como a qualquer outro elemento, portanto, não é sua posição no "mundo atual",

28 "Secundam rationem ponit ibi: inconveniens igitur est et cetera. Et dicit quod inconveniens est quod antiqui naturales reliquerunt tractare de fortuna, sive putaverunt fortunam esse sive non: quia si putaverunt fortunam esse, inconveniens fuit quod de ea non determinaverunt; si vero non putaverunt fortunam esse, inconveniens fuit quod ea aliquando usi sunt; sicut Empedocles, qui dixit quod aer non semper adunatur superius supra terram quasi hoc ei sit naturale, sed quia ita accidit a casu. Dicit enim quod quando mundus est factus, lite distinguente elementa, accidit quod aer se collegit in istum locum, et sicut tunc cucurrit, ita semper stante isto mundo cursum habebit: sed multoties in aliis mundis, quos ponebat infinities fieri et corrumpi, ut supra dictum est, aer aliter ordinatur inter partes universi. Et similiter dicebat quod plurimae partes animalium fiunt a fortuna; sicut quod in prima constitutione mundi fiebant capita sine cervice". 
mas a característica compartilhada pelos elementos de serem os primeiros princípios que podem constituir um ou vários mundos. Aliás, deve-se notar que para Empédocles conforme DSS, c. 1, os primeiros princípios são finitos e ocupam todos os "espaços", uma vez que não há vazio e que, além disso, a amizade e a luta, os dois motores do mundo, fazem as coisas estarem sempre em movimento ("...aut finita, sicut Empedocles quatuor elementa, et cum bis duo moventia, amicitiam et litem"; DSS, c. 1).

O impacto que a cosmologia de Empédocles causou não só na antiguidade, mas, e, sobretudo, nos séculos XII-XIII, pode ter sido ofuscado pela ênfase exagerada que os historiadores da filosofia conferem a cosmologia aristotélica para o período mencionado. Isso, entretanto, não retira a relevância de Empédocles, mais especificamente se se considera seu modo de pensamento do mundo (e dos mundos): a configuração atual das coisas poderia ser de outro modo, nem por isso elas perderiam sua naturalidade ou retornariam ao caos. Ademais, é preciso ressaltar, a naturalidade das coisas não advém de uma causa no sentido escolástico de um creator, pois Empédocles permanece fiel a máxima "ex nibilo nibil fieri". Assim sendo, as hipóteses de

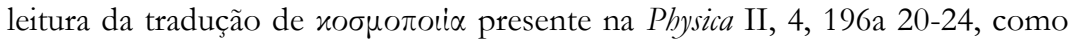
creatiomundi e facturamundi respectivamente, são muitas, pois, para Empédocles ("latino"), há creatio ou facturamundi sem um creator: uma negação que assegura a naturalidade da cosmologia (scientia naturalis) de Empédocles no Ocidente latino.

\section{Referências}

AERTSEN, J. A. (2012). Medieval Philosophy as Transcendental Thought: From Philip the Chancellor (ca. 1225) to Francisco Suárez. Leiden-Boston: Brill.

. (1996). Medieval Philosophy \& the Transcendentals: the Case of Thomas Aquinas.Leiden: Brill.

ARISTOTELIS. (1962). Physica (trad. Moerbeke). In: Aristotelis opera cum Averroiscommentariis, vol. IV, Venetiis apud Junctas 1562-1574, repr. Frankfurt a.M.: Minerva.

ARISTOTELIS. (1962). Physica (trad. Miguel Escoto). In: Aristotelis opera cum Averroiscommentariis, vol. IV, Venetiis apud Junctas 1562-1574, repr. Frankfurt a.M.: Minerva. 
ARISTOTELIS. (1884). Physica (texto Grego). In: TOMÁS DE AQUINO. In octolibros physicorum Aristotelis expositio. Opera omnia iussu impressa que Leonis XIII P. M. edita, vol. II, Roma: Typographia Polyglotta.

ARISTOTELES LATINUS VII 1. (1990). Physica (translation Iacobus Veneticus). Leiden, New York: Brill.

ARISTOTELES LATINUS VII 2. (1990). Physica (translatioVaticana). Leiden, New York: Brill.

ARISTOTLE. (1999) Physics. Tr. by R. P. Hardie e R. K. Gaye. In: Commentary on Aristotle's Physics. Notre Dame, Indiana: Dumb ox Books.

ARISTOTELIS. (1950). Physica. W. D. Ross (ed.). Oxford: Oxford University Press.

ARISTÓTELES. (1996.). Física. Trad. José Luiz Calvo Martínez. Madri: Consejo Superior de Investigaciones Científicas.

ARISTOTELE. (1993). Fisica. Trad. Antonio Russo e Oddone Longo. Roma: Editori Laterza.

ARISTOTELES. (1987). Physik. Trad. Hans Günter Zekl. Hamburg: Felix Meiner Verlang.

ARISTÓTELES. (2009). Física I e II. Trad. Lucas Angioni. Campinas, SP: Editora da UNICAMP.

ARISTOTE. (1993). Physique. Trad. Pierre Pellegrin. Paris: Éditions Nathan.

AVICENNA LATINUS. (1980). Liber De Philosophia prima sive Scientia divina, I$X$. Édition critique de la traduction latine médiévale, par S. Van Riet. Louvain, E. Peeters - Leiden, E. J. Brill.

BOLLACK, J. (1965-1969). Empedocle. Paris: LesÉditions de Minuit.

BOURKE, V. (1991). "Introduction". In: Commentary on Aristotle's Physics. Notre Dame, Indiana: New Haven Yale University Press. p. xvii-xxix.

BRAMS, J.; VENHAMEL, W. (eds.) (1989). Guillaume de Moerbeke: Recueil d'études à l'occasiondu 700e anniversaire de samort (1286). Leuven: Leuven University Press. 
BRAMS, J.; VUILLEMIN-DIEM, G. (1989). Note concernant la collation d'un deuxième manuscript grec de la Physique per Guillaume de Moerbeke. In: .; VENHAMEL, W. (eds.). Guillaume de Moerbeke: Recueil d'études à l'occasiondu 700e anniversaire de samort (1286). Leuven: Leuven University Press. p. 185-192.

BRAMS, J. (1989). La 'RecensioMatritensis de laPhysique. In: VENHAMEL, W. (eds.). Guillaume de Moerbeke: Recueil d'études à l'occasiondu 700 e anniversaire de samort (1286). Leuven: Leuven University Press. p. 193-220.

- (1986). Das Verhältniszwischen der TranslatioVaticana und der TranslatioVetus der Aristotelischen Physik. Miscellanea Mediaevalia, v. 18, p. 190-214.

- (1986). VUILlEMIN-DIEM, G. Physica Nova und Recensio Matritensis - Wilhelm von Moerbekesdoppelte Revision der PhysicaVetus. Miscellanea Mediaevalia, v. 18, p. 215-284.

. (2001). LesTraductions de Guillaume de Moerbeke. In: HAMESSE, J. (ed.). Les Traducteurs au travail leurs Manuscritsetleurs Méthodes. Belgium: Brepols. p. 231-256.

CLAGETT, M. (1959). The science of mechanics in the Middle Ages. Madison: Univ. of Wisconsin.

DE LIBERA. (1998). Alain. A Filosofia Medieval. São Paulo: Edições Loyola.

Genesis. (1891). In: Vulgata e Editionis Sixti V. etClementis VIII. Disponível em:

http://www.vatican.va/archive/bible/nova_vulgata/documents/novavulgata _index_lt.html. Acessoem 05 de jun. 2016.

GERSON, P. L. (1993). Plotinus's Metaphysics: Emanation or Creation? The Review of Metaphysics, v. 46, n. 3, p. 559-574.

JAEGER, W. (1952). La Teologia de los Primeros Filosofos Griegos. México-Buenos Aires: Fondo de Cultura Económica.

LEEMANS, P.; BRAMS, J. (2009).The Aristoteles Latinus: Project a survey. Revista Portuguesa de História do Livro e da Edição, ano XII, n. 24, p. 105-124. 
MANSION, A. (1932). Sur le texte de la version latine médiévale de la Métaphysique et de la Physique d'Aristote dans les éditions des Commentaires de saint Thomas d'Aquin. Revue néo-scolastique de philosophie, v. 34, n. 33, p. 6569.

MINIO-PAUELLO, L. (1950). Note sull' Aristotele latino medievale. Revista di Filosofia Neoscolastica, v. 42, p. 222-231.

- (1952). Iacobus Veneticus Grecus: Canonist and Translator of Aristotle. Traditio, v. 8, p. 265-304.

MONDOLFO, R. (1968). O bomem na cultura antiga. São Paulo: Mestre Jou. . (1959). El pensamiento antiguo. Buenos Aires: Editorial Losada.

. (1952). El infinitoen el pensamiento de la antiguedadclásica. Buenos Aires: Editorial Universitaria de Buenos Aires.

PLATO LATINUS. (1975). Timaeus a Calcidio Translatus Commentario que Instructus. KLIBANSKY, Raymond (ed.). Londinii: In aedibus Instituti Warburgianiet E. J. Brill.

SANTOS, Evaniel Brás. (2015a). Causalidade e Natureza na Cosmologia de Tomás de Aquino. Philósophos, Goiânia, v. 20, n. 1, p. 95-124.

. (2015b). Tomás e o problema do movimento elementar: notas sobre In Physica, II, 1, n. 3, 1-8. In: CARVALHO, Marcelo; PICH, Roberto Hofmeister; SILVA, Marco Aurélio Oliveira; OLIVEIRA, Carlos Eduardo. (Org.). Filosofia Medieval. Coleção XVI Encontro ANPOF, São Paulo: ANPOF. p. 243-260.

- (2014). A locomoção natural dos elementos: Tomás de Aquino, crítico de Aristóteles latino. Analytica, Rio de Janeiro, v. 18, p. 123-151.

. (2013). A estrutura e o devir dos seres em Tomás de Aquino. In: CARVALHO, Marcelo; FIGUEIREDO, Vinicius. (Org.). Filosofia Antiga e Medieval. São Paulo: ANPOF, v. 1, p. 151-174.

SORABJI, R. (1983). Time, Creation and the Continum: Theories in Antiquity and the Early Middle Ages. Ithaca, New York: Cornell University Press. 
TAYLOR, C. R.(1998). Aquinas, the 'Plotiniana Arabica', and the Metaphysics of Being and Actuality. Journal of the History of Ideas, v. 59, n. 2, p. 217-239.

TOMÁS DE AQUINO. (1884). In octolibrosphysicorum Aristotelis expositio. Opera omniaiussu impressa que Leonis XIII P. M. edita, vol. II, Roma: Typographia Polyglotta.

. (1886). In libros Aristotelis De caelo et mundo. Opera omniaiussu impressa que Leonis XIII P. M. edita, vol. III, Roma: Typographia Polyglotta.

.(1888). Pars prima Summae Theologia e a quaestione I ad quaestionem XLIX. Opera omniaiussu impensa que Leonis XIII P.M. edita, vol. IV. Roma: Typographia Polyglotta.

. (1892). Prima secundae Summa e Theologia e a quaestione LXXI ad quaestionem CXIV. Opera omnia iussu impensa que Leonis XIII P. M. edita, vol. VII. Roma: Typographia Polyglotta.

. (1918-1930). Summa contra gentiles. Ed. Leon., vol. XIII-XV. Roma.

. (1925). Quaestiones Disputatae de Potentia Dei. Ed. P. Mandonnet, vol.

II, Parisiis: P. Lethielleux.

- (1929) Scriptum Super Libros Sententiarum Magistri Petri Lombardi. Ed. P. MandonnetVol. 1-2, Parisiis: P. Lethielleux.

- (1954). SanctiThomae de Aquino super Librum De Causis Expositio. H. D. Saffrey (org.). Fribourg: Textus philosophici Friburgenses 4/5.

. (1969). De substantiis separatisad fratrem Raynaldum de Piperno. Ed. H.F. Dondaine. Ed. Leon., vol. XL, Romae : Ad Sanctae Sabinae.

. Super Boetium De Trinitate. Expositio libri Boetii De ebdomadibus. Opera omnia iussu Leonis XIII P. M. Edita, vol. L, Commissio Leonina - Roma Paris: Éditions du Cerf, 1992.

. (2000). Quaestio Disputata De Spiritualibus Creaturis. Ed. J. COS. Ed. Leon., vol. XXIV-2. Roma - Paris: Commissio Leonina - Les Éditions du Cerf.

O'BRIEN, D. (1969.). Empedocles' cosmiccycle: a reconstruction from the fragments and secondary sources. Cambridge: The University Press. 
VERNANT, J-P. (1978). Sobre a atualidade do helenismo: entrevista com Jean-Pierre Vernant. Discurso, São Paulo, n. 8, p. 169-182.

. (1990). Mito e Pensamento entre os gregos: estudos de psicologia histórica. Rio de Janeiro: Paz e Terra.

. (1995). Introducción: El hombre griego. In: (ed.). El hombre griego. Madrid: Alianza Editorial. p. 11-33. . (2006). Mito e religião na Grécia antiga. São Paulo: Martins Fontes.

ZARIROPULO, J. (1953). Empédocle d'Agrigente. Paris: Les Belles Lettres.

WOLFF, C. (1977). Christiani Wolffii Philosophia prima sive ontologia. Hildesheim: Olms. 